\title{
National Coal Quality Inventory (NaCQI) and U.S. Geological Survey Coal Quality Databases
}

\section{National Coal Quality Inventory (NaCQI)}

Coal will remain a very significant part of U.S. energy needs (fig.1), even though there will continue to be concern about environmental impacts associated with its use. Currently, about 88 percent of U.S. coal production is used by electric utilities. The remaining 12 percent is either exported or used domestically for other industrial applications, such as coke for steel production.

Debates generated by the 1990 Amendments to the Clean Air Act have highlighted the critical need for current, accurate, reliable, and comprehensive information on the quality of our domestic coal resources. To address this need the U.S. Geological Survey (USGS), the Electric Power Research Institute (EPRI) and its member utilities, geological surveys in coal producing states, and the Department of Energy's

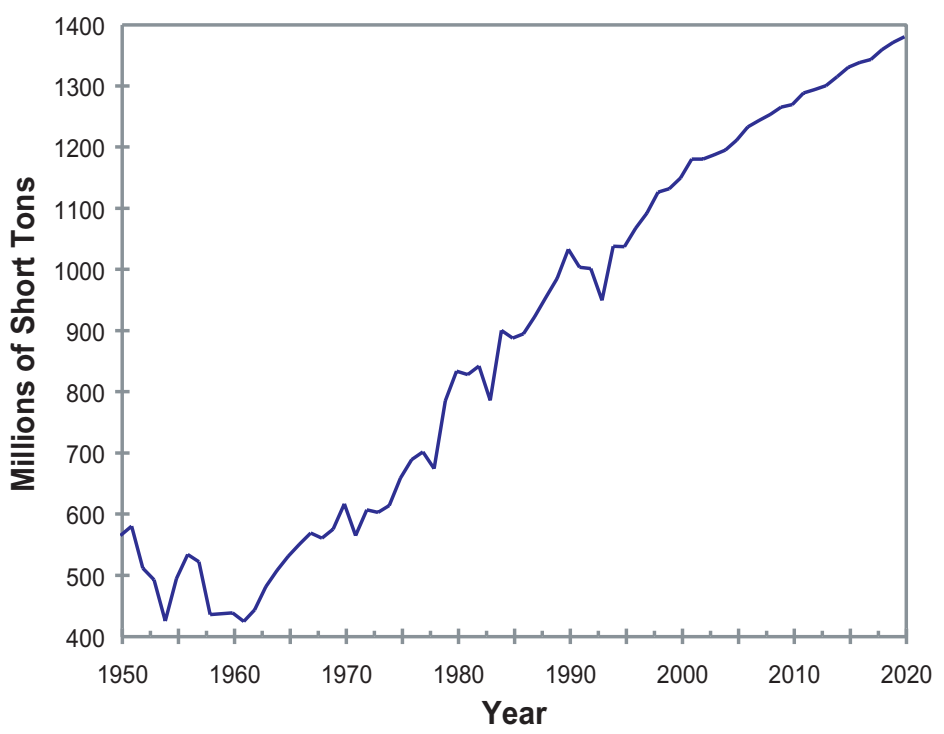

Figure 1. Coal production in the United States, from 1950 projected through 2020. Data from the Energy Information Administration (1997a, b).

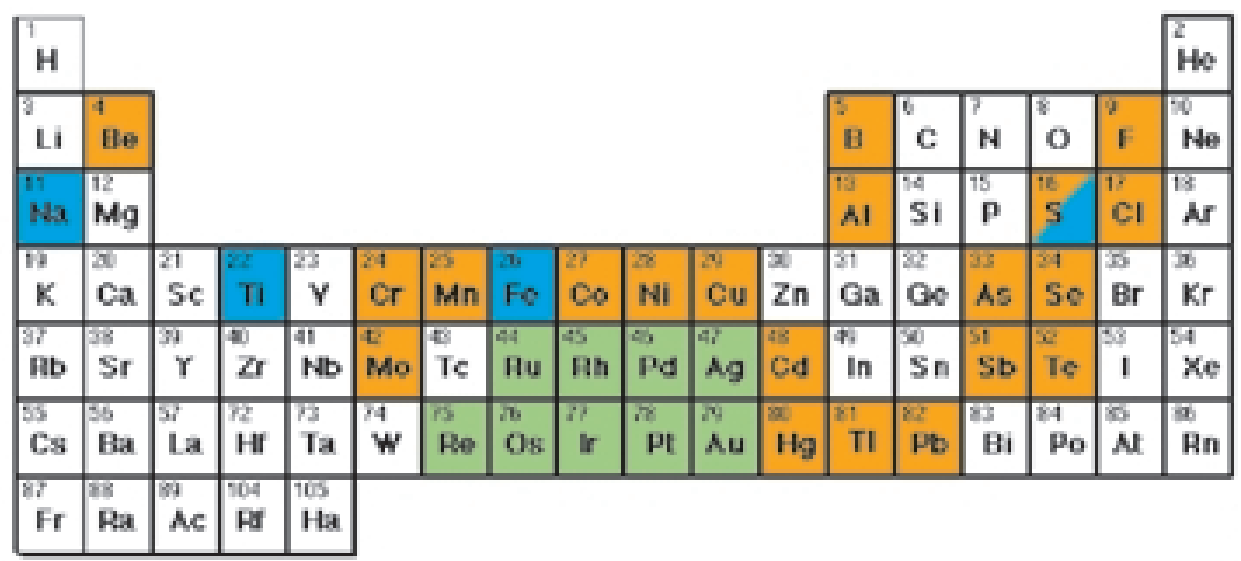

\begin{tabular}{|c|c|c|c|c|c|c|c|c|c|c|c|c|c|}
\hline $\begin{array}{l}58 \\
\mathrm{Ce}\end{array}$ & $\begin{array}{l}5 \pi \\
\mathrm{Pr}\end{array}$ & Nd & \begin{tabular}{|l|}
51 \\
$\mathrm{Pm}$
\end{tabular} & \begin{tabular}{|l|}
$\mathrm{S}$ \\
$\mathrm{Sm}$
\end{tabular} & Eu & $\begin{array}{l}54 \\
\text { Gd }\end{array}$ & Tb & Dy & Ho & Er & $\begin{array}{l}\text { F } \\
\text { Tm }\end{array}$ & \begin{tabular}{|l|}
0 \\
$Y b$
\end{tabular} & $\begin{array}{l}\text { P1 } \\
\text { Lu }\end{array}$ \\
\hline Th & $\mathrm{Pa}$ & u & $\mathrm{Np}$ & $\begin{array}{l}94 \\
P_{u}\end{array}$ & $\begin{array}{l}\mathrm{S} \\
\mathrm{Am}\end{array}$ & \begin{tabular}{|l|} 
S \\
Cm
\end{tabular} & Ek & $\mathrm{cr}$ & $\overline{\mathrm{A}}$ & $\mathrm{Fm}$ & \begin{tabular}{|l|} 
icid \\
Mdd
\end{tabular} & \begin{tabular}{|l|}
$\mathrm{N}^{2}$ \\
No
\end{tabular} & Lr \\
\hline
\end{tabular}

Elements of environmental or human health concern

Elements of technological concern

\section{Elements having economic byproduct potential}

Figure 2. Periodic table of the elements highlighting elements of environmental, human health, and technological concern, as well as elements having economic byproduct potential. Most of the highlighted elements and about 30 others are part of the current USGS analytical scheme used for analysis of coal samples collected for NaCQI.
Federal Technology Center (FETC) have created the National Coal Quality Inventory (NaCQI). The overall objective of this partnership is to generate reliable, accurate, and accessible information on the quality of the major coal beds that will be mined in the U.S. during the next 20-30 years. The new, comprehensive coal-quality database will augment the existing coalquality database (COALQUAL) maintained by the USGS.

The participants in this partnership (USGS, EPRI, FETC, state geological surveys, participating utilities, the Environmental Protection Agency, and the National Mining Association) are prioritizing the major coal-producing beds based on anticipated production trends, regional economic significance, and available coal-quality data. The sampling strategy is intended to obtain a balance of sample types (core/channel, run-of-mine, raw/clean, power-plant feed) to better represent coal to be used in the future. A schedule has been developed for the collection, handling, and characterization of the coal samples. 
The current USGS analytical scheme will constitute the basic characterization of each sample. This scheme includes determining moisture, ash, heat value, sulfur forms, ash fusion temperatures, and the concentrations of about 60 major, minor, and trace elements (fig. 2). ASTM standard coal characteristics (for example, carbon, hydrogen, nitrogen, oxygen calorific value, and sulfur form data) will be generated by either commercial laboratories or by participating utilities. Additional sample characterization (for example, mineralogy, modes of occurrence determinations, leaching behavior, fouling characteristics) will be used to address the specific coal-quality issues in different regions. Overall, the number of samples collected, the supplementary characterization, and the number of core samples obtained will be determined by the level of project funding. It is anticipated that at least 1,000 coal samples will be collected and analyzed under the $\mathrm{NaCQI}$ project.

Sample collection began in 1998; sample collection and characterization will require three years. University and other coal research organizations will participate in NaCQI to help address relevant technological, environmental, economic, and geologic problems related to coal quality. NaCQI will follow uniform policies for respecting the confidentiality requirements of all participants.
Anticipated products of the NaCQI project will have importance on a national scale. The data resulting from NaCQI will lead to better understanding of patterns and trends of coal characteristics on a regional scale for each of the major coal basins. This knowledge should result in more reliable prediction and planning for developing the nation's coal resources in a manner that will best safeguard air and water quality.

\section{Existing USGS Coal Quality Database}

The data generated by the NaCQI project will augment the coal quality information collected by the USGS since the mid-1970's (fig. 3).

The USGS maintains COALQUAL, the largest existing database that contains coal-quality information on U.S. coal beds. The database is available as a USGS Open-File Report (Bragg and others, 1998). Information in this database can be used to locate coal having quality characteristics desirable for specific technological uses and for environmental compatibility.

\section{International Coal Quality Database}

The USGS, in cooperation with many coal-producing countries, will create a database that contains coal-quality

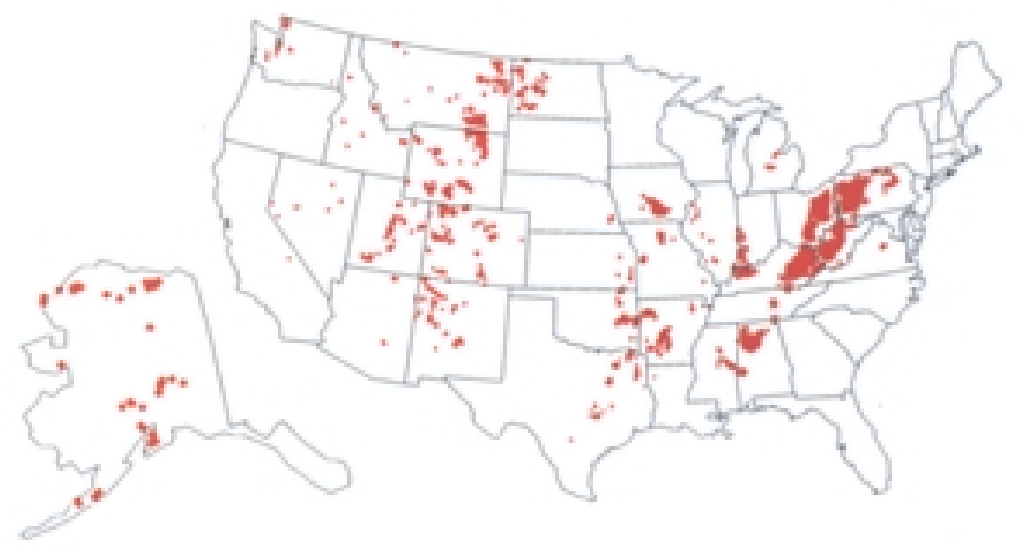

Figure 3. Coal sample localities from COALQUAL (the U.S. Geological Survey geochemical database), July 1994. COALQUAL is part of the USGS National Coal Resources Data System. 